\title{
CARACTERIZAÇÃO DO ABASTECIMENTO DE ÁGUA NA COMUNIDADE NORTE-MINEIRA DE POÇÕES
}

\author{
Odilene Antunes RIBEIRO ${ }^{1}$ \\ Artur José FERREIRA NETO ${ }^{2}$ \\ Paulo Borges de FREITAS JÚNIOR ${ }^{3}$ \\ Victor Rodrigues ARAGÃO ${ }^{4}$
}

${ }^{1}$ Faculdades Santo Agostinho. E-mail: odileneretiro@ hotmail.com
${ }^{2}$ Faculdades Santo Agostinho. E-mail: engenharia.ajfn@gmail.com
${ }^{3}$ Faculdades Santo Agostinho. E-mail: paulo_freitasjr@ hotmail.com
${ }^{4}$ Universidade Federal de Santa Maria - UFSM. E-mail: aragaovr@gmail.com

Recebido em: 25/04/2015 - Aprovado em: 21/08/2015 - Disponibilizado em: 30/10/2015

\begin{abstract}
RESUMO: Este trabalho teve por objetivo caracterizar o abastecimento de água na comunidade de Poções, localizada no município norte-mineiro de Bocaiúva. Para sua idealização foram promovidos questionários à comunidade envolvida, além da utilização de tecnologias computacionais que envolveram os softwares Spring 5.2.2., Fragstats, ArcGis 9.3. e o modelo digital de elevação (MDE), para melhor caracterização da área que envolve o abastecimento. Através dos resultados obtidos, foi possível concluir que a água que abastece a comunidade de Poções é proveniente do rio Cachoeiras, da chuva e de cisternas, e em nenhum caso apresentou tratamentos, e ainda assim foi constatada a utilização da mesma ao consumo humano; atividade dominante relativa ao consumo médio dentre outras quatro atividades. A água então não se encontrou, no período de estudo, dentro dos padrões recomendados à potabilidade, apresentando coliformes termotolerantes e turbidez em níveis indesejáveis, desta forma, recomenda-se, em função das características locais, a utilização de filtros de atividade lenta, bem como do tratamento da água do rio Cachoeiras, no qual abastece a população envolvida, visando a melhoria da qualidade sanitária e a profilaxia de doenças. Palavras-chave: Água, Tratamentos, Potabilidade, Filtros de atividade lenta, Profilaxia de doenças.
\end{abstract}

\section{WATER SUPPLY CHARACTERISTICS IN POÇÕES'S COMMUNITY, LOCATED IN THE NORTH OF MINAS GERAIS}

\begin{abstract}
This study aimed to characterize the water supply in Poções's community, located in the north-mining town of Bocaiúva. For it idealization were promoted questionnaires to the community involved, besides the use of computer technologies involving the Spring 5.2.2 software., Fragstats, ArcGIS 9.3. and the digital elevation model to better characterize the area surrounding the supply. Through the results, it was concluded that the water that supplies the Poções community comes from the Cachoeiras river, rain and tanks, and in no case had treatments, yet was found from using it for human consumption; dominant activity on the average consumption among four other activities. The same was not found in the study period, within the potability standards recommended, with fecal coliform and turbidity in undesirable levels in this way, it is recommended, depending on local characteristics, the use of slow activity filters, and the treatment of Cachoeiras river water, which supplies the population involved in order to improve the sanitary quality and prophylaxis of diseases.
\end{abstract}

Keywords: Water, Treatments, Potability, Slow activity filters, Prophylaxis of diseases. 


\section{INTRODUÇÃO}

A água é um bem público de domínio da união, representa fonte de vida, e é, sobretudo, o principal constituinte de todos os organismos vivos. Apesar das inúmeras tecnologias da atualidade, os seres humanos não são capazes de se adaptar à vida sem água. Entretanto, a irracionalidade quanto ao desperdício e a degradação dos recursos hídricos superaram o instinto de sobrevivência, colocando em risco até mesmo sua própria espécie (MORAES e JORDÃO, 2002; BARBOSA, 2008).

Eventualmente, a contaminação da água é causada pelo despejo inadequado de efluentes, mormente, pelas atividades antropogênicas relacionadas ao esgoto doméstico e proveniente das atividades industriais. Independentemente da natureza dos efluentes, esses têm a capacidade de deteriorar a qualidade dos corpos receptores, presentes tanto nas áreas urbanas quanto nas rurais (PEREIRA, 2004; DEZOTTI et al., 2008).

A comunidade rural, foco deste estudo, tem enfrentado inúmeros problemas relacionados à seca e a falta de água potável para consumo, uma vez que, a água tratada não tem chegado a essas populações. Muitas comunidades têm o seu abastecimento feito por poços artesianos, captação direta no curso hídrico ou captação de água da chuva (SAAE, 2015).

Figura 1 - Mapa de localização dos municípios envolvidos no estudo.

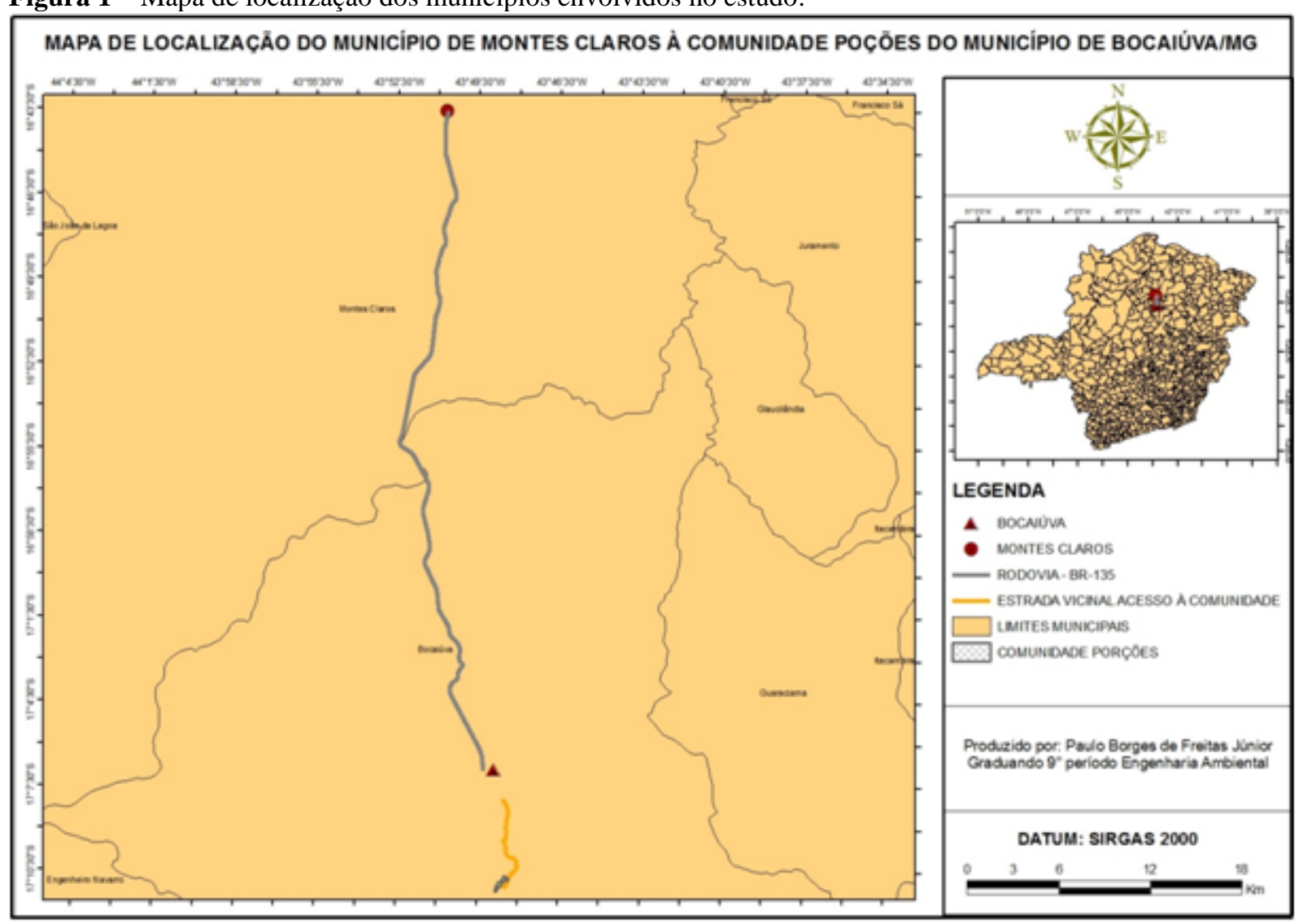

Fonte - Próprios autores. 
Diante das dificuldades encontradas para o abastecimento de água em comunidades rurais, o presente trabalho tem por objetivo caracterizar as formas de abastecimento e consumo da água na comunidade de Poções, localizada no município de Bocaiúva, Minas Gerais.

\section{METODOLOGIA}

Este trabalho foi realizado em março de 2014, na comunidade de Poções, pertencente ao município de Bocaiúva $\left(17^{\circ} 06^{\prime} 28^{\prime \prime S}\right.$ e $43^{\circ}$ 48' 54"O) (SAAE, 2015), norte de Minas Gerais. Para chegar até o local de estudo foi necessário seguir pela BR-135 até Bocaiúva e em seguida fazer o deslocamento até a comunidade através de uma estrada vicinal rural por aproximadamente $8 \mathrm{~km}$. A comunidade tem
43 residências e aproximadamente 150 habitantes. A figura 1 apresenta o percurso realizado.

Para caracterizar a situação da população residente na comunidade e dos recursos hídricos presentes no estudo, foram realizados questionários e uma reunião com os líderes comunitários para a verificação das formas de abastecimento de água na comunidade, seus devidos usos e as dificuldades encontradas no abastecimento.

A sub-bacia do rio Cachoeiras está inserida na bacia do rio Jequitaí-Pacuí e ambas estão fixadas na bacia do Rio do São Francisco, apresentando uma área de 10364,31 ha, de acordo com a figura 2 .

Figura 2 - Bacias hidrográficas de ordem superior à bacia hidrográfica do rio Cachoeiras.

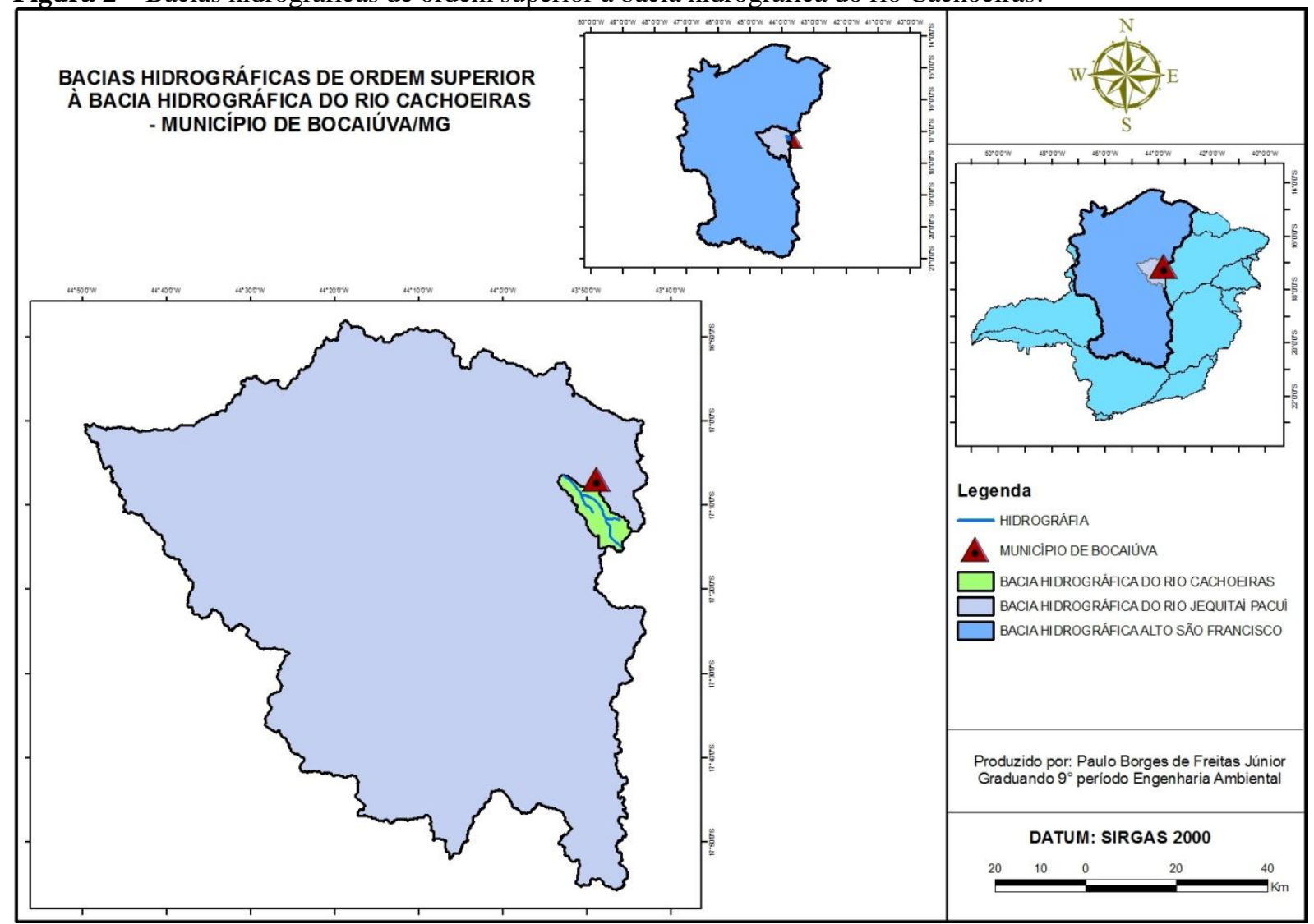

Fonte - Próprios autores. 
A representação da vegetação da área de estudo foi desenvolvida a fim de proporcionar uma maior abrangência da pesquisa, onde foram realizadas coletas em campo dos pontos de GPS para facilitar a classificação supervisionada por região, no software Spring 5.2.2, com definições de 4 classes temáticas de uso do solo (Figura 3). Para o cálculo da área $(\mathrm{CA})$ e a quantidade de fragmentos (NP) em cada classe, utilizou-se métricas da paisagem CA e NP do software Fragstats, em função de representações gráficas.

E para a delimitação das áreas de topo de morro, utilizou-se o modelo digital de elevação (MDE) da área em estudo e o software ArcGis 9.3.

Figura 3 - Bacias hidrográficas de ordem superior à bacia hidrográfica do rio Cachoeiras.

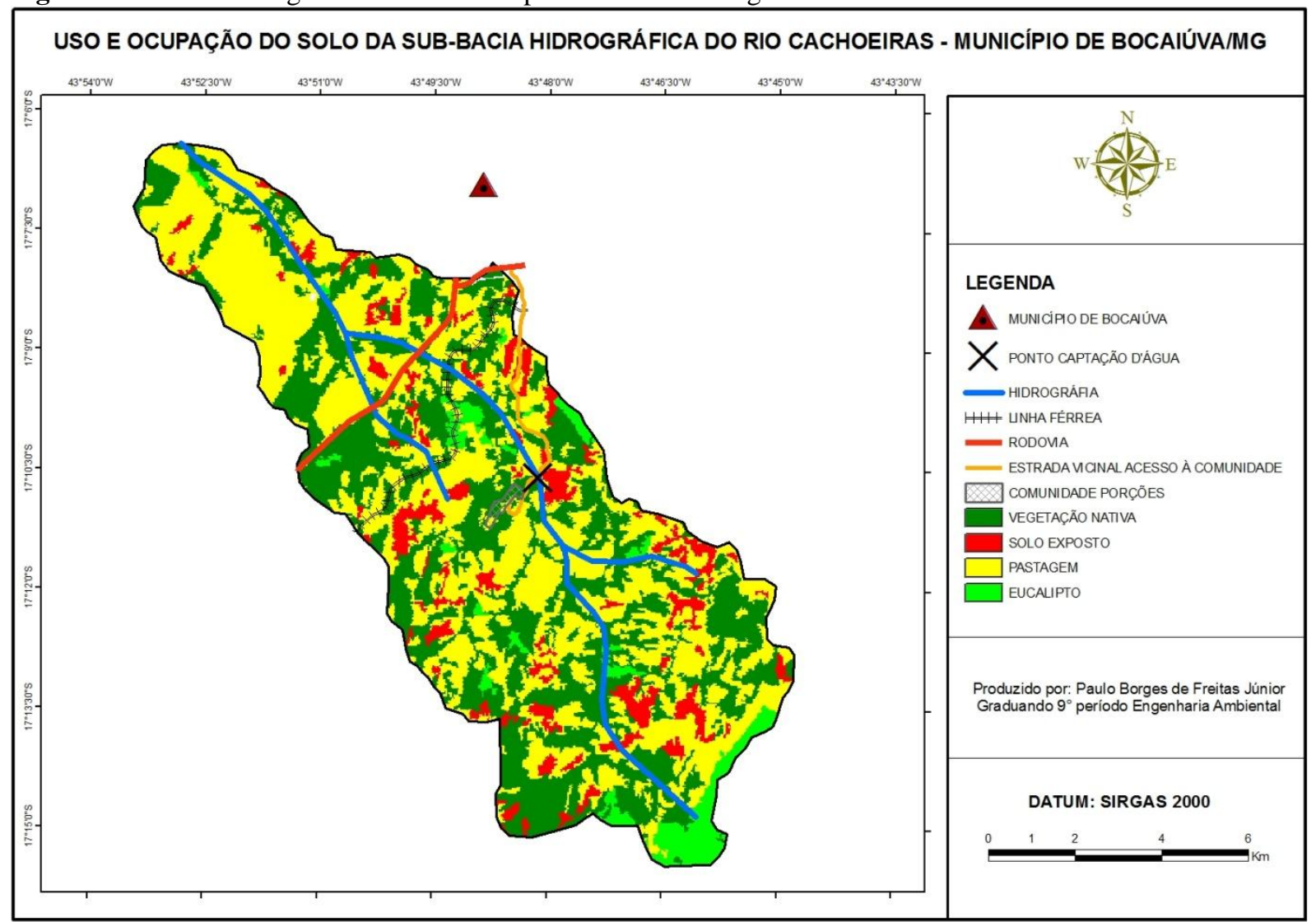

Fonte - Próprios autores.

\section{RESULTADOS E DISCUSSÃO}

A comunidade de Poções é através de cisternas. Foi ainda encontrado no abastecida através da captação de água do rio local um poço artesiano, que já se encontra Cachoeiras (Figura 4A), captação da água da instalado, no entanto não está em chuva, que é um projeto de parceria entre a funcionamento, pois está em uma propriedade Companhia de Desenvolvimento dos Vales do particular e o proprietário não disponibiliza do

São Francisco e do Parnaíba uso da água. (CODEVASF) e a prefeitura (Figura 4B) e

Revista da Universidade Vale do Rio Verde, Três Corações, v. 13, n. 2, p. 407-414, 2015 
Figura 4 - Formas de abastecimento de água na Comunidade de Poções. A) Captação de água do Rio Cachoeiras. B) Captação de água de chuva através de caixas d'água com capacidade de 16 mil litros.

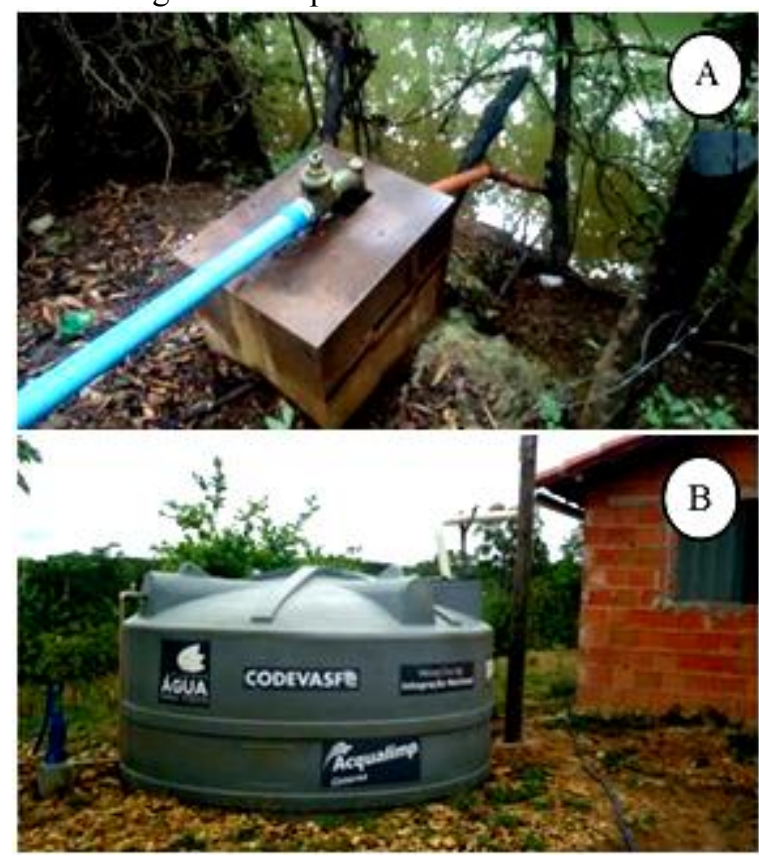

Fonte - Próprios autores.

A captação da água ocorre quatro vezes por semana, onde a mesma é bombeada e armazenada em dois reservatórios de que apresentam capacidade de armazenamento de 5.000 e 19.000 litros, sendo que o primeiro é de estrutura metálica e o segundo é feito de alvenaria (Figuras 5A e 5B). Os dois reservatórios apresentam visualmente bom estado de conservação. Após o armazenamento nos reservatórios a água é distribuída para toda a comunidade.
Figura 5 - Reservatórios de água na comunidade de Poções. A) Reservatório de metal com capacidade de 5.000 litros de água. B) Reservatório de alvenaria com capacidade para 19.000 litros de água.

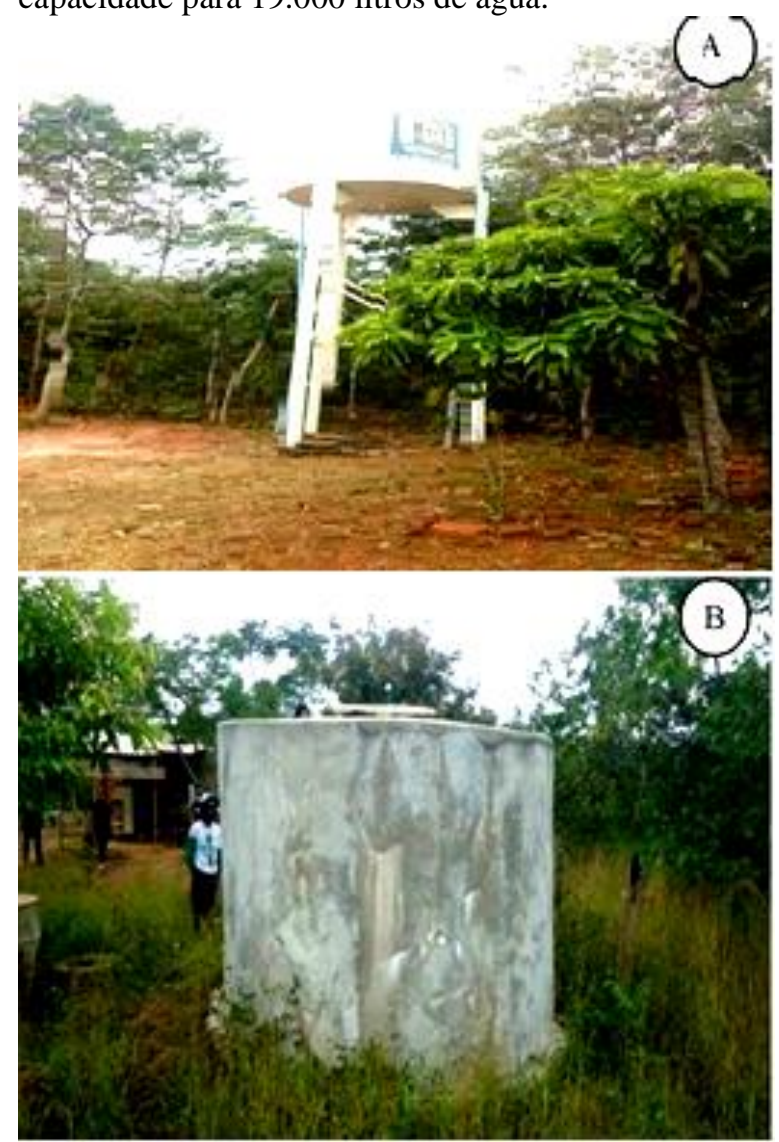

Fonte - Próprios autores.

Em relação ao uso da água na comunidade, a mesma apresenta funções diversas, desde a utilização doméstica, uso na agricultura e pecuária, dentre outros. Vale ressaltar que esta água não recebe nenhum tipo de tratamento, ainda assim é utilizada para consumo humano. Entretanto, a grande maioria dos moradores compra água mineral para o seu consumo em Bocaiúva. Na tabela 1 são apresentadas as formas de captação de água com os respectivos usos e o percentual de moradores da comunidade que fazem o uso desta água.

Revista da Universidade Vale do Rio Verde, Três Corações, v. 13, n. 2, p. 407-414, 2015 
Tabela 1 - Formas de captação ponderadas.

\begin{tabular}{|c|c|c|}
\hline F.C.A. ${ }^{1}$ & U.A. $^{2}$ & Q.P. ${ }^{3}$ \\
\hline Rio Cachoeiras & $\mathrm{I}, \mathrm{C}, \mathrm{D}$ & $50 \%$ \\
\hline Água da chuva & $\mathrm{I}, \mathrm{C}, \mathrm{D}$ & $20 \%$ \\
\hline Cisterna & $\mathrm{I}, \mathrm{D}$ & $10 \%$ \\
\hline Água mineral comprada & $\mathrm{C}$ & $20 \%$ \\
\hline Poço artesiano & $\mathrm{I}, \mathrm{C}, \mathrm{D}$ & $0 \%$ \\
\hline Total & & $100 \%$ \\
\hline
\end{tabular}

Legenda:

${ }^{1}$ Forma de Captação de Água;

${ }^{2}$ Usos da Água;

${ }^{3}$ Quantidade de Pessoas;

I - Irrigação;

C - Consumo Humano;

D - Dessedentação de animais.

Fonte - Próprios autores.

Para o levantamento do consumo médio de água na comunidade Poções, levou-se em consideração a quantidade pessoas residentes no local, a quantidade de animais (bovinos, suínos, equinos e aves) e também a presença de agricultura irrigada. A tabela 2 apresenta o consumo médio de água em um dia na comunidade em estudo.

Tabela 2 - Consumo médio de água em um dia.

\begin{tabular}{cccc}
\hline Uso & Quantidade & $\begin{array}{c}\text { Litros } \\
\text { (L/uso.dia) }\end{array}$ & $\begin{array}{c}\text { Total } \\
\text { (L/dia) }\end{array}$ \\
\hline Habitantes & 150 & 100 & 15000 \\
Bovinos & 45 & 55 & 2475 \\
Equinos & 30 & 50 & 1500 \\
Suínos & 20 & 16 & 320 \\
Galinhas & 120 & 0,17 & 20,4 \\
\hline
\end{tabular}

Fonte - Próprios autores.

A grande maioria da água utilizada na comunidade é destinada ao consumo humano, seja nas atividades domésticas ou mesmo consumo próprio. Em virtude disso, torna-se necessário buscar alternativas para o tratamento adequado dessa, visto que, a mesma não apresenta qualidade adequada para o consumo humano, uma vez tendo a presença de coliformes termotolerantes em amostras de $100 \mathrm{ml}$ e elevada turbidez (8,02 NTU) (SAAE, 2015).

Em relação ao cálculo da área (CA) e a quantidade de fragmentos (NP) em cada classe, os resultados obtidos foram arranjados nas figuras 6 e 7 .

Figura 6 - Área das classes na sub-bacia do rio Cachoeiras.
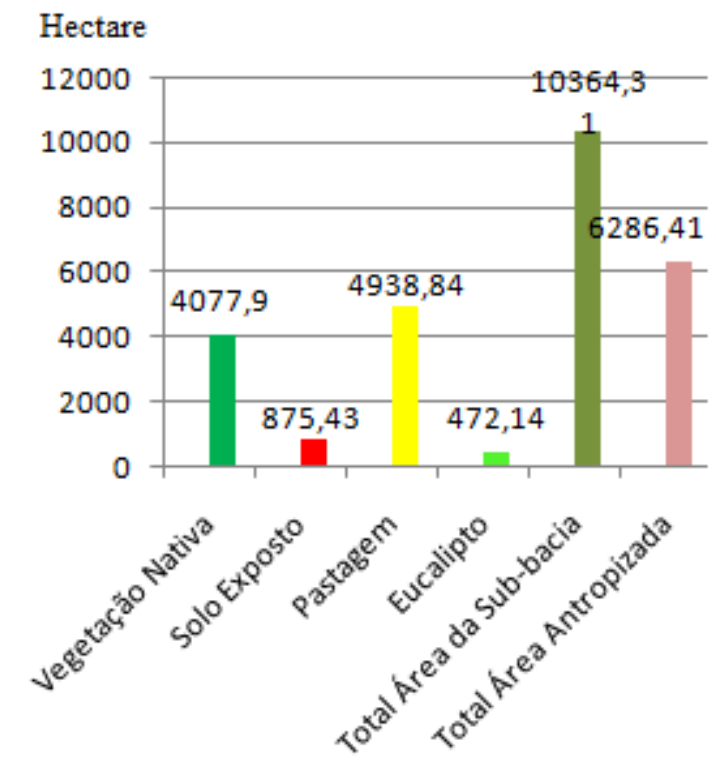

Fonte - Próprios autores. 
Figura 7 - Número de Fragmentos das classes na subbacia do rio Cachoeiras.
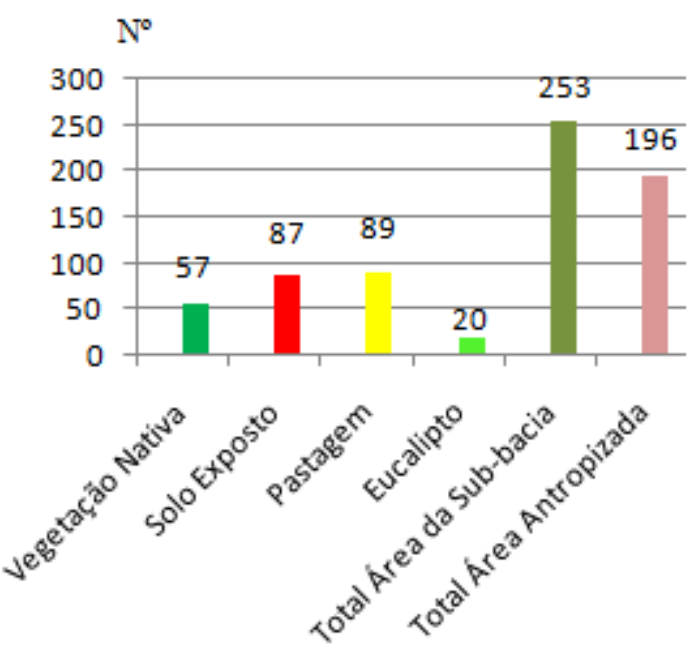

Fonte - Próprios autores.

Por meio das figures 6 e 7, e das visitas in loco, foi possível estimar a vegetação nativa predominante sendo do Cerrado, com cerca de $31 \%$, sendo deste percentual, $8 \%$ de mata de galeria, com área total de 4077,9 ha, não apresentando vegetação de campo limpo, vereda e mata-seca. Por apresentar baixa percentagem de vegetação nativa, notou-se intenso uso do solo (área de pastagem 47\%, solo exposto $8 \%$, eucalipto $6 \%$, com área total de $6286,41 \mathrm{ha})$.

Em relação à delimitação das áreas de topo de morro, notou-se a presença de 4 regiões, representando 2,33\% da bacia (Figura 8). De acordo com os cursos hídricos inseridos na sub-bacia do rio Cachoeiras. Desta forma, tendo em vista as características locais, pode ser viável a utilização de um filtro de natureza lenta ao tratamento da água destinada, mormente, ao consumo humano.

Figura 8 - Áreas de Preservação Permanente da sub-bacia hidrográfica do Rio Cachoeiras.

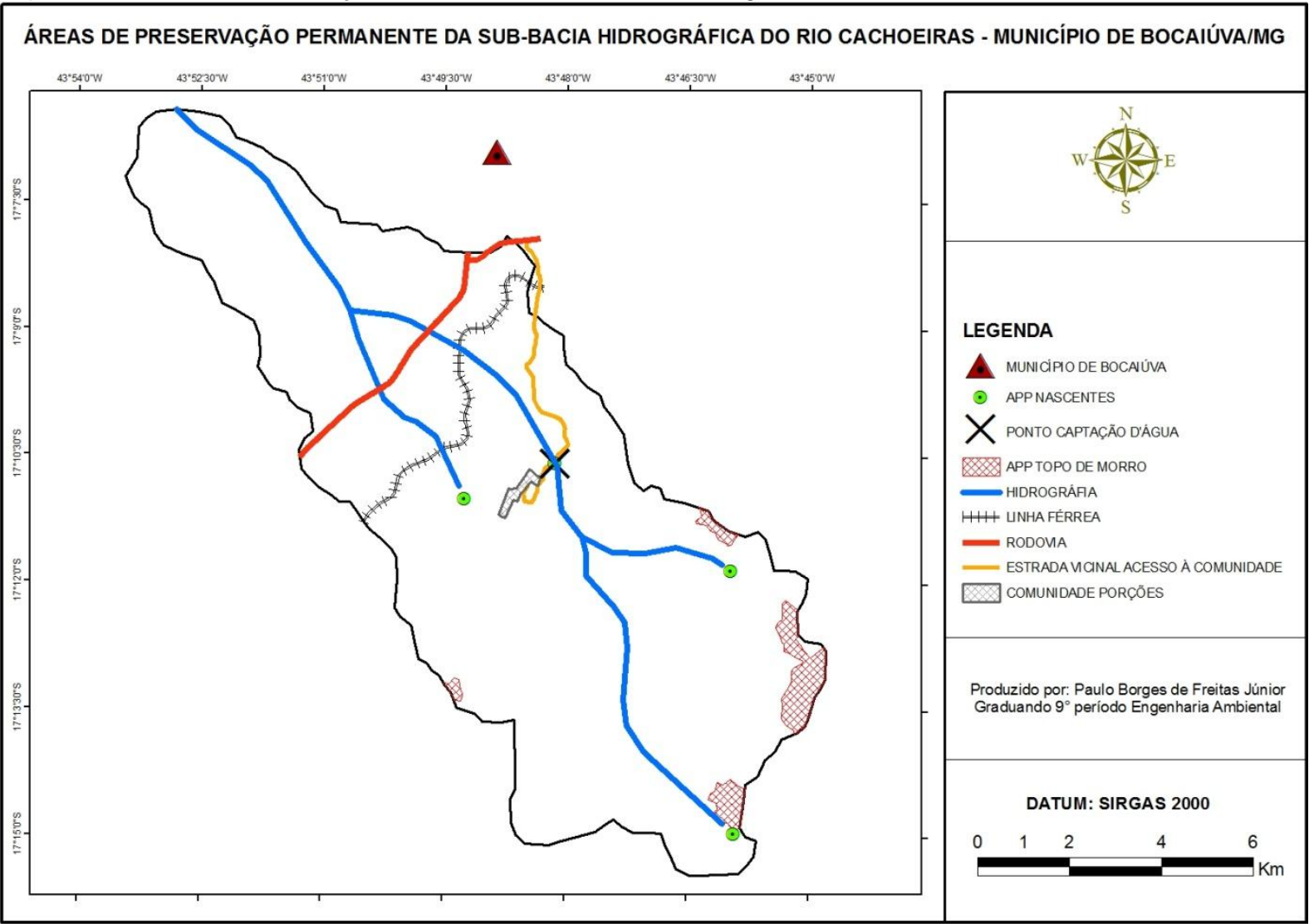

Fonte - Próprios autores.

Revista da Universidade Vale do Rio Verde, Três Corações, v. 13, n. 2, p. 407-414, 2015 
Por meio de levantamento visual voltando na figura 3, foi possível observar que a mata ciliar está presente e bem preservada no decorrer de todos os cursos hídricos que abastecem a sub-bacia, mesmo apresentando $8 \%$ do total da vegetação nativa local.

Já através do questionário feito aos moradores da comunidade, fora informado a presença de seis barramentos ao longo do rio. Sendo notória a presença de 54 barraginhas de contenção de água de chuva no decorrer da estrada vicinal rural até a comunidade. Essas têm por objetivo a contenção de água da chuva, diminuindo assim as erosões nas estradas de terra e o assoreamento dos cursos hídricos, e permite também a dessedentação de animais, comprovando assim a existência de uma vasta área de pastagem inseridas na sub-bacia do rio Cachoeiras.

\section{CONSIDERAÇÕES FINAIS}

Através deste trabalho, ficou clara a necessidade da comunidade de Poções em buscar uma forma de tratamento para o abastecimento doméstico, pois esse não se encontra dentro dos parâmetros permitidos para consumo humano; evitando assim doenças de veiculação hídrica.

Uma possível solução para a população da comunidade seria o tratamento da água do rio Cachoeiras que abastece a população. O tratamento poderia ocorrer através de um filtro de atividade lenta. Produtos dessa natureza detêm a capacidade de remoção de microrganismos, sendo reconhecida como a tecnologia mais apropriada para tratar água para abastecimento de pequenas comunidades por ser de simples construção, operação e manutenção, o que representa custos geralmente acessíveis ao produtor rural.

\section{REFERÊNCIAS}

BARBOSA, Francisco. Ângulos da água: desafios da integração. Belo Horizonte: Editora UFMG, 2008. 366 p.

DEZOTTI, M.; et al. Processos e Técnicas para o Controle Ambiental de Efluentes Líquidos. Série Escola Piloto de Engenharia Química COPPE/UFRJ. V.5. Rio de Janeiro: Epapers. 2008.

MORAES, D. S. de L.; JORDÃO. B. Q. Degradação de recursos hídricos e seus efeitos sobre a saúde humana. 2002. Rev. Saúde Pública, 2002; 36(3): 370-4.

PEREIRA, R. S. Identificação e caracterização das fontes de poluição em sistemas hídricos. Revista Eletrônica de Recursos Hídricos. IPH-UFRGS. V. 1, n. 1. p. 20-26. 2004.

SAAE - Serviço Autônomo de Água e esgoto de Bocaiúva. Tratamento de Água. Disponível em: <

http://www.bocaiuva.mg.gov.br/index.php?opti on $=$ com_content $\&$ view $=$ article $\& i d=83 \&$ Itemid =54> Acesso em: 28 de abril 2015 . 